\title{
PHENOLICS CONTENT AND ANTIOXIDANT ACTIVITY OF SOUR CHERRY EXTRACTS WITH SUGAR ADDITION
}

\author{
M. Kopjar a*, D. Alilovićb ${ }^{b}$ T. PožrL ${ }^{c}$, V. PiližOta and A. Pichler ${ }^{a}$ \\ ${ }^{a}$ Faculty of Food Technology, Josip Juraj Strossmayer University of Osijek, Franje Kuhača 20, 31000 Osijek. \\ Croatia \\ ${ }^{b}$ Faculty of Agronomy and Food Technology, University of Mostar; Biskupa Čule bb, 88000 Mostar. Bosnia and \\ Hercegovina \\ ${ }^{\mathrm{c}}$ Biotechnical Faculty, University of Ljubljana, Jamnikarjeva 101, 1000 Ljubljana. Slovenia
}

(Received: 10 February 2017; accepted: 27 March 2017)

\begin{abstract}
Sour cherry puree was prepared with addition of sucrose or trehalose $(5 \%$ and $10 \%)$. After stabilization of the mixture (puree with sugars), extracts were prepared and contents of phenolics and anthocyanin, polymeric colour percentage, and antioxidant activity were determined. Extracts were stored for 65 days at $4{ }^{\circ} \mathrm{C}$. Control sample was extract of sour cherry puree without sugars. After extraction, extracts with $10 \%$ of sucrose or trehalose had higher phenolic content than the control sample. Anthocyanin content was higher in extracts with trehalose addition. During storage of extracts, samples with trehalose had higher retention of phenolic and anthocyanins than other samples. Addition of sucrose and trehalose as well as their amounts affected the stabilities of phenolics, anthocyanins, and antioxidant activity in sour cherry extracts
\end{abstract}

Keywords: sour cherry extracts, sucrose, trehalose, phenolics, anthocyanins

Very often, extraction of the valuable compounds is conducted for their preservation and further utilisation in products. It is well known that phenolics, secondary metabolites, play a very important part in the quality of foods either through impact on the sensory characteristics or nutrition value of the product. Phenolics are known for beneficial effects on the human health. Their positive effect is ascribed to their antioxidant potential due to their possibility of acting as chain breakers or radical scavengers, which depends on their chemical structure (Chung et al., 1998; Rice-Evans, 2001; Cheynier, 2005; El Gharras, 2009). Phenols, as fruit constituents, are also important for their effect on colour, taste, and nutritional properties of fruit and their products (CHEYNIER, 2005). Anthocyanins are a group of pigments of characteristic flavonoid structure with colour ranging from red to violet, depending on the source plant. They play critical role in the evaluation of the colour quality of many fruit and their products, but, unfortunately, they are very unstable during processing and under storage conditions (StintZing \& CARLE, 2004). Due to their very attractive colour, they can be used as colorants instead of synthetic ones, and at the same time, they have antioxidant properties. As phenolics are important constituents of foods, it is important to preserve them also in extracts that could be used as additives to processed foods, processed beverages, herbal products, dietary supplements, and functional foods. In this study, influence of sugars on the stability of the phenolics and anthocyanins in the sour cherry extracts during storage was examined. Sucrose is a disaccharide that is commonly used in food industry. Trehalose is also a disaccharide that is getting more attention in food industry every day. Trehalose and sucrose

\footnotetext{
* To whom correspondence should be addressed.

Phone: +38531224300; fax: +38531207115; e-mail: Mirela.Kopjar@ptfos.hr
} 
are isomers with the same chemical formula but different structures resulting in different behaviour (Branca et al., 1999; PATIST \& ZoERB, 2005). Next to positive influence on the fruit product quality, trehalose also has some health benefits (NETA et al., 2000; PATRA et al., 2009; VAN CAN et al., 2012).

Extraction of phenolics is usually performed by treatment of raw material with the solvent. In this study, since it has already been proven that during processing under different conditions sugars can affect phenolics and anthocyanins (Lewis et al., 1995; RizzoLo et al., 2003; DuAngmal et al., 2008; KopJAR et al., 2008, 2011, 2012; LonČAriĆ et al., 2016; NowicKA \& WoJDYŁo, 2016), extracts were prepared from sour cherry puree mixed with different amounts (5 and 10\%) of sugars, sucrose or trehalose. In this way, extraction of phenolics from prepared mixtures was evaluated in comparison to sample without sugar addition. Obtained extracts were used for determination of contents of phenolics and anthocyanins, polymeric colour, and antioxidant activity. Extracts were stored in order to evaluate the stability of phenolics and anthocyanins and the effect of sugars on it during storage.

\section{Materials and methods}

\subsection{Preparation of sour cherry extracts}

Sour cherry (Prunus cerasus L.) was bought at local market and stored at $-20{ }^{\circ} \mathrm{C}$ before preparation of puree. The fruit was washed, the pits were removed, and it was blended (Braun Multiquick Professional 600 Watt Turbo) to obtain puree. Sour cherry puree was mixed and well homogenized with $5 \%$ or $10 \%$ of sugar (sucrose or trehalose). Mixtures of puree and sugars were left for five days at room temperature in closed container in the dark to stabilize, and then the extraction was conducted. Ten grams of mixture of sour cherry puree and sugars was mixed with $50 \mathrm{ml}$ of acidified methanol (concentrated $\mathrm{HCl}$ :methanol - 0.5:100). The mixture was left for $1 \mathrm{~h}$ at room temperature. After extraction, the mixture was filtered and the extracts were recovered. Extracts were stored in glass jars in the dark at $4{ }^{\circ} \mathrm{C}$ for 65 days.

\subsection{Evaluation of phenolic compounds}

The total phenolic content in the samples were determined by Folin-Ciocalteu method (Singleton \& Rossi, 1965). Results are expressed as g of gallic acid equivalents per 1 litre of sample (g GAE/l).

\subsection{Evaluation of monomeric anthocyanin content and polymeric colour}

The monomeric anthocyanin pigment content of extracts and polymeric colour were determined by the $\mathrm{pH}$-differential method (GIUSTI \& WROLSTAD, 2001). Results are expressed as $\mathrm{mg}$ of cyanidin-3-glucoside equivalents per 1 litre of sample (mg CGE/l).

\subsection{Evaluation of antioxidant activity}

ABTS assay was conducted according to the method by ARNAO and co-workers (2001) and DPPH assay according to BRAND-WILLIAMS and co-workers (1995). Results of antioxidant activity were expressed as nmol of Trolox equivalents per $\mathrm{ml}$ of sample (nmol TE/ml). 


\subsection{Statistical analysis}

Phenolic and anthocyanin contents, polymeric colour, and antioxidant activity were evaluated by the analysis of variance and Fisher's least significant difference test with significance defined at $\mathrm{P}<0.05$. All statistical analyses were carried out using the software program STATISTICA 8.0 (StatSoft, Tulsa). Each evaluation was conducted in triplicates, and results were expressed as means \pm standard deviation.

\section{Results and discussion}

Studies were conducted on the influence of sugars on phenolics and anthocyanins retention in different fruit products prepared by different methods under different conditions. In many cases (DuAngmal et al., 2008; Kopjar et al., 2008, 2011, 2012; LonČArić et al., 2016) it was proven that trehalose had stabilizing effect on those compounds, thus in this study, the studied extracts were prepared from sour cherry puree and sour cherry puree with addition of sugars. In this way, we wanted to investigate influence of sugars (sucrose and trehalose) and their amount (5 and 10\%) on the stability of phenolics and anthocyanins and antioxidant activity during storage of the extracts. As a control sample, extract of sour cherry without addition of sugars was prepared. Results of the evaluation of phenolics and anthocyanins contents and polymeric colour of sour cherry extracts during storage are presented in Table 1. In comparison to the control sample, addition of $5 \%$ of sugars had no effect on the phenolics content, while with addition of $10 \%$ sugars, higher phenolic compounds content was determined. During storage of the extracts, the content of phenolic compounds decreased. Addition of sucrose, 5 or 10\%, did not have positive effect on the phenolic compounds content. Retention of phenolics in the control sample and extracts with sucrose were both around 78\%. Extracts with trehalose had higher phenolic compounds content than other samples and higher retention of phenolics was achieved, 83 and $85 \%$ for extracts with 5 and $10 \%$ of trehalose, respectively.

Table 1. Phenolic compounds, anthocyanins, and polymeric colour in sour cherry extracts with addition of sugars during storage

\begin{tabular}{lccc}
\hline Samples & $\begin{array}{c}\text { Phenolic content } \\
(\mathrm{g} \mathrm{GAE} / \mathrm{l})\end{array}$ & $\begin{array}{c}\text { Anthocyanin content } \\
(\mathrm{mg} \mathrm{CGE} / \mathrm{l})\end{array}$ & $\begin{array}{c}\text { Polymeric colour } \\
(\%)\end{array}$ \\
\hline After preparation & & & $23.59 \pm 0.44^{\mathrm{a}}$ \\
Extract & $3.87 \pm 0.09^{\mathrm{a}}$ & $509.48 \pm 1.37^{\mathrm{a}}$ & $23.40 \pm 0.49^{\mathrm{a}}$ \\
Extract+5\% sucrose & $3.99 \pm 0.02^{\mathrm{a}}$ & $511.94 \pm 1.71^{\mathrm{a}}$ & $21.72 \pm 0.64^{\mathrm{b}}$ \\
Extract+10\% sucrose & $4.12 \pm 0.03^{\mathrm{b}}$ & $515.79 \pm 1.36^{\mathrm{b}}$ & $21.59 \pm 0.32^{\mathrm{b}}$ \\
Extract+5\% trehalose & $3.97 \pm 0.03^{\mathrm{a}}$ & $521.43 \pm 1.28^{\mathrm{c}}$ & $18.43 \pm 0.46^{\mathrm{c}}$ \\
Extract+10\% trehalose & $4.17 \pm 0.09^{\mathrm{b}}$ & $527.17 \pm 1.54^{\mathrm{d}}$ & \\
After storage & & & $47.21 \pm 0.36^{\mathrm{a}}$ \\
Extract & $3.02 \pm 0.07^{\mathrm{a}}$ & $447.50 \pm 1.27^{\mathrm{a}}$ & $51.25 \pm 0.31^{\mathrm{b}}$ \\
Extract+5\% sucrose & $3.12 \pm 0.07^{\mathrm{a}}$ & $425.06 \pm 1.01^{\mathrm{b}}$ & $45.29 \pm 0.25^{\mathrm{c}}$ \\
Extract+10\% sucrose & $3.15 \pm 0.05^{\mathrm{a}}$ & $461.44 \pm 1.32^{\mathrm{c}}$ & $41.98 \pm 0.39^{\mathrm{d}}$ \\
Extract $+5 \%$ trehalose & $3.33 \pm 0.06^{\mathrm{b}}$ & $498.52 \pm 1.08^{\mathrm{d}}$ & $40.38 \pm 0.25^{\mathrm{e}}$ \\
Extract+10\% trehalose & $3.55 \pm 0.06^{\mathrm{c}}$ & $504.05 \pm 1.11^{\mathrm{e}}$ & \\
\hline
\end{tabular}

Within the same column means followed by different letters are significantly different at $\mathrm{P} \leq 0.05$ (ANOVA, Fisher's LSD). 
There was no statistical difference between the anthocyanin contents of the extract with $5 \%$ sucrose and control sample, while in the extract with $10 \%$ sucrose, significantly higher anthocyanin content was determined. Both extracts with trehalose had higher anthocyanin contents than the control sample and both extracts with sucrose. During storage of the extracts, degradation of anthocyanins occurred. The extract with $5 \%$ sucrose had lower anthocyanin content, while all other samples had higher anthocyanin contents compared to the control. All extracts, except extract with $5 \%$ of sucrose $(83 \%)$, had higher retention of the pigment than the control sample (87\%). Increasing the sucrose content to $10 \%$ resulted in retention of anthocyanins up to $89 \%$. Both extracts with trehalose had $95 \%$ retention of the anthocyanins. Positive effect of some additives (palm sugar, erythritol, steviol glycoside, xylitol, and inulin) on phenolics content and antioxidant activity of sour cherry puree and trehalose and maltose in freeze-dried sour cherry puree was observed also by other authors NowickA \& WoJdyŁo (2016) and LonČARIĆ and co-workers (2016).

The control sample and the extract with 5\% sucrose had the same values of polymeric colour. Extracts with 10\% trehalose had the lowest polymeric colour. During storage, as anthocyanin content decreased, increase of polymeric colour percentage occurred. Extract with the lowest anthocyanin content (extract with $5 \%$ of sucrose) had the highest polymeric colour values, while samples with the highest anthocyanin content (extract with trehalose) had the lowest polymeric colour. The large increase in polymeric colour values together with corresponding loss of monomeric anthocyanins during storage may be ascribed to condensation reactions of the anthocyanins with other phenolics (HAGER et al., 2008).

Mechanism of anthocyanins degradation involves water hydrolysis of the glycosidic bond in anthocyanins, which leads to formation of unstable anthocyanidins, followed by opening of the pyrilium ring and formation of chalcones, and brown end products (ERLANDSON $\&$ Wrolstad, 1972). Additionally, in the presence of oxygen, water can increase the oxidation rate of anthocyanins (JACKMAN \& SMITH, 1992). It has been found that sugar molecules are effective in binding water, and from our results it can be concluded that trehalose is more effective in that, since after extraction, higher anthocyanin content was determined in those samples. Trehalose has superior effect on "destructuring" the network of water and slowing down its dynamics. Steric hindrance developed by disaccharides, which can prevent or slow down the nucleophilic attacks of water, was probably more pronounced in samples with trehalose than with sucrose, because of the higher structure stability of trehalose against hydrolysis (BORDAT et al., 2004). The stability of trehalose or formation of stable complex of trehalose and phenolics prior to extraction could be possible explanations of its positive influence on phenolics during the storage of extracts. Trehalose can form a stable intramolecular complex with unsaturated compounds that possess the cis-type olefinic double bond (OKU et al., 2003). Other compounds that have unsaturated bonds similar in shape to the cis-type olefinic double bond, like benzene and $p$-cresol, can bind with trehalose in aqueous solutions but not with other disaccharides (SAKAKURA et al., 2011). This phenomenon that could be responsible for the stabilising effect of trehalose on phenolics can be explained by the unique nature of trehalose, and it was stated that the aromatic ring attaches to the dehydrated, hydrophobic pocket of trehalose, forming the complex (SAKAKURA et al., 2011). In addition, extracts with trehalose addition had higher retention of phenolics and anthocyanins indicating that stabilising effect of trehalose on those compounds remained also in extracts.

For evaluation of antioxidant activity two methods, ABTS and DPPH, were applied, which are often used for antioxidant activity evaluation of fruit products and preparations. Results of ABTS method showed much higher antioxidant activity of the extracts after 
preparation as well as after storage (Table 2). Samples with sugar addition had higher antioxidant activity. During storage, antioxidant activity decreased, but the tendency remained. Addition of sucrose and trehalose as well as their amount had great effect on phenolic compounds, anthocyanins, and antioxidant activity. When applying DPPH method, antioxidant activity values of the control sample and the extract with $5 \%$ sucrose were the same. The extract with trehalose had the highest antioxidant activity. After storage, a decrease in antioxidant activity could be observed. The control sample had the lowest antioxidant activity. Extracts with 5\% sugar had slightly higher antioxidant activity, while extracts with $10 \%$ sugar had the highest values. The highest decrease of antioxidant activity was in extract with $5 \%$ trehalose, $48 \%$. The lowest decrease was observed in extracts with $10 \%$ sugar, 39\%. Application of ABTS method revealed different tendency. Extracts with sugars had higher antioxidant activity than control sample, but there was no difference between the different amounts of the same sugar. After storage, there was a difference between the extracts with the different amounts of the same sugar. The control sample had the lowest and extracts with trehalose had the highest antioxidant activity. The highest decrease of antioxidant activity was in extracts with sucrose, $12 \%$, while in extracts with trehalose, there was only $5 \%$ decrease. The difference between DPPH and ABTS methods comes from the different selectivity of used free radicals toward antioxidants depending on their structure. Antioxidant activity of phenolic compounds depends on a number of $\mathrm{OH}$-groups and their position. $\mathrm{OH}-$ groups on 3'-, 4'-, 5'- position of B-ring of flavonoids increase the antioxidant activity of the compounds in contrast to the phenolics with one hydroxy group (HeIM et al., 2002). In our study, different free radicals were used for the determination of the antioxidant activity, with different reactivity with the phenolic compounds depending on their structure (CAMPOS \& Lissi, 1997). The ABTS $^{-+}$has low selectivity in reactions with H-atom donors, since it is reacting with any hydroxylated aromatics independently of their real antioxidant potential. However, the DPPH does not react with flavonoids, which contain no OH-groups on B-ring, nor with aromatic acids containing only one OH-group (RoGINSKY \& Lissi, 2005).

Table 2. Antioxidant activity ( $\mathrm{nmol} \mathrm{TE} / \mathrm{ml})$ of sour cherry extracts with addition of sugars during storage

\begin{tabular}{lll}
\hline Samples & DPPH method & ABTS method \\
\hline After preparation & & \\
Extract & $912.48 \pm 3.85^{\mathrm{a}}$ & $4195.86 \pm 8.01^{\mathrm{a}}$ \\
Extract+5\% sucrose & $918.94 \pm 8.10^{\mathrm{a}}$ & $4464.12 \pm 2.76^{\mathrm{b}}$ \\
Extract+10\% sucrose & $986.71 \pm 8.30^{\mathrm{b}}$ & $4463.54 \pm 6.88^{\mathrm{b}}$ \\
Extract+5\% trehalose & $1014.46 \pm 5.40^{\mathrm{c}}$ & $4829.01 \pm 2.72^{\mathrm{c}}$ \\
Extract+10\% trehalose & $1086.79 \pm 8.49^{\mathrm{d}}$ & $4826.64 \pm 1.94^{\mathrm{c}}$ \\
After storage & & \\
Extract & $499.45 \pm 2.84^{\mathrm{a}}$ & $3813.79 \pm 4.32^{\mathrm{a}}$ \\
Extract $+5 \%$ sucrose & $539.71 \pm 3.15^{\mathrm{b}}$ & $3885.54 \pm 4.59^{\mathrm{b}}$ \\
Extract $+10 \%$ sucrose & $599.43 \pm 4.51^{\mathrm{c}}$ & $3929.06 \pm 5.81^{\mathrm{c}}$ \\
Extract $+5 \%$ trehalose & $526.33 \pm 3.21^{\mathrm{d}}$ & $4547.86 \pm 2.45^{\mathrm{d}}$ \\
Extract $+10 \%$ trehalose & $664.48 \pm 3.48^{\mathrm{e}}$ & $4619.34 \pm 3.56^{\mathrm{e}}$ \\
\hline
\end{tabular}

Within the same column means followed by different letters are significantly different at $\mathrm{P} \leq 0.05$ (ANOVA, Fisher's LSD). 


\section{Conclusions}

Nowadays, the fortification of the foods with phenolics is a common way to increase the nutritional value and to obtain products with higher antioxidant properties beneficial for human health. Also, phenolics are beneficial to other quality properties. From our study, it is evident that it is necessary to have in mind that interactions between the compounds during the preparation and storage of products or formulations, in our case extracts, can occur. Those interactions can cause retention of some valuable compounds. The aim of this study was to determine the stability of phenolics, anthocyanins, and antioxidant activity of the sour cherry extracts and influence of sugars on the stability of mentioned compounds. Obtained results showed that the retention of phenolics and anthocyanins as well as antioxidant activity was the highest in samples prepared with addition of trehalose.

This work has been supported by the Croatian Science Foundation under the project Trehalose: fruit product quality improvement project (6949). We are grateful to Hayashibara, Nagase Group, Japan for generous donation of trehalose and maltose.

\section{References}

Arnao, M.B., Cano, A. \& Acosta, M. (2001): The hydrophilic and lipophilic contribution to total antioxidant activity. Food Chem., 73, 239-244.

Brand-Williams, W., Cuvelier, M.E. \& Berset, C. (1995): Use of a free radical method to evaluate antioxidant activity. LWT - Food Sci. Technol., 28, 25-30.

Bordat, P., Lerbret, A., Demaret, J.-P., Affouard, F. \& Descamps, M. (2004): Comparative study of trehalose, sucrose and maltose in water solutions by molecular modelling. Europhys. Lett., 65, 41-47.

Branca, C., Faraone, A., Magazu, S., Maisano, G., Migliardo, F., Migliardo, P. \& Villari, V. (1999): Structural and dynamical properties of trehalose-water solutions: Anomalous behaviour and molecular models. -in: Pandalai, S.G. (Ed.) Recent research developments in physical chemistry, Vol. 3, Transworld Research Network, Trirandrum, India pp. 361-386.

Campos, A.M. \& Lissi, E.A. (1997): Kinetics of the reaction between 2,2'-azibobis(3-ethylbenzothiazoline-6sulfonic acid) (ABTS) derived radical cation and phenols. Int. J. Chem. Kinet., 29, 219-224.

Cheynier, V. (2005): Polyphenols in foods are more complex than often thought. Am. J. Clin. Nutr., 81, 223S-229S

Chung, K.T., Wong, T.Y., Huang, Y.W. \& Lin, Y. (1998): Tannins and human health. A review. Crit. Rev. Food Sci. Nutr., 38, 421-464.

Duangmal, K., Saicheua, B. \& SueEprasan, S. (2008): Colour evaluation of freeze-dried roselle extract as a natural food colorant in a model system of a drink. LWT - Food Sci. Technol., 41, 1437-1445.

El Gharras, H. (2009): Polyphenols: food sources, properties and applications - a review. Int. J. Food Sci. Tech., $44,2512-2518$.

Erlandson, J.A. \& Wrolstad, R.E. (1972): Degradation of anthocyanins at limited water concentrations. J. Food Sci., 37, 592-595.

Giusti, M.M. \& Wrolstad, R.E. (2001): Current protocols in food analytical chemistry. John Wiley \& Sons, Inc., New York. pp. F1.2.1-F1.2.13.

Hager, A., Howard, L.R., Prior, R.L. \& Brownmiller, C. (2008): Processing and storage effects on monomeric anthocyanins, percent polymeric color, and antioxidant capacity of processed black raspberry products. $J$. Food Sci., 73, H134-H140

Heim, K.E., Tagliaferro, A.R. \& Bobilya, D.J. (2002): Flavonoid antioxidants: Chemistry, metabolism and structure-activity relationship. J. Nutr. Biochem., 13, 572-584.

JACKMAn, R.L. \& Sмith, J.L. (1992): Anthocyanins and betalains. -in: HendRY, G.A.F. \& Houghton, J.D. (Eds) Natural food colorants. Blackie, Glasgow, pp. 182-241. 
Kopjar, M., Jakšı́́, K. \& Piližota, V. (2012): Influence of sugars and chlorogenic acid addition on anthocyanin content, antioxidant activity and color of blackberry juice during storage. J. Food Proc. Pres., 36, 545-552.

Kopjar, M. \& Piližota, V. (2011): Prevention of thermal degradation of anthocyanins in blackberry juice with addition of different sugars. CyTA - J. Food, 9, 237-242.

Kopjar, M., Piližota, V., Hribar, J., SimČič, M., Zlatič, E. \& Nedić Tiban, N. (2008): Influence of trehalose addition and storage conditions on the quality of strawberry cream filling. J. Food Eng., 87, 341-350.

Lewis, C.E., WaLker, J.R.L. \& LanCaster, J.E. (1995): Effect of polysaccharides on the colour of anthocyanins. Food Chem., 54, 315-319.

Lončarić, A., Pichler, A., Trtinjak, I., Piližota, V. \& Kopjar M. (2016): Phenolics and antioxidant activity of freeze-dried sour cherry puree with addition of disaccharides. LWT - Food Sci. Technol., 73, 391-396.

Neta, T., TAKADA, K. \& Hirasawa, M. (2000): Low-cariogenicity of trehalose as a substrate. J. Dent., 28, 571-576.

NowickA, P. \& WoJDYŁo, A. (2016): Stability of phenolic compounds, antioxidant activity and colour through natural sweeteners addition during storage of sour cherry puree. Food Chem., 196, 925-934.

Oku, K., Watanabe, H., Kubota, M., Fukuda, S., Kurimoto, M., Tujisaka, Y., Komori, M., Inoue, Y. \& Sakurai, M. (2003): NMR and quantum chemical study on the $\mathrm{OH}^{\cdots} \pi$ and $\mathrm{CH}^{\cdots} \cdots \mathrm{O}$ interactions between trehalose and unsaturated fatty acids: Implication for the mechanism of antioxidant function of trehalose. J. Am. Chem. Soc., $125,12739-12748$.

Patist, A. \& Zoerb, H. (2005): Preservation mechanisms of trehalose in food and biosystems. Colloid Surface B., $40,107-113$.

Patra, F., Tomar, S.K. \& Arora, S. (2009): Technological and functional applications of low-calorie sweeteners from lactic acid bacteria. J. Food Sci., 74, R16-R23.

Rice-Evans, C. (2001): Flavonoid antioxidants. Curr. Med. Chem., 8, 797-807.

Rizzolo, A., Nani, R.C., Viscardi, D., Bertolo, G. \& Torreggiani, D. (2003): Modification of glass transition temperature through carbohydrates addition and anthocyanin and soluble phenol stability of frozen blueberry juices. J. Food Eng., 56, 229-231.

Roginsky, V. \& Lissi, E.A. (2005): Review of methods to determine chain-breaking antioxidant activity in food. Food Chem., 92, 235-254.

Sakakura, K., OKabe, A., OKu, K. \& Sakurai, M. (2011): Experimental and theoretical study on the intermolecular complex formation between trehalose and benzene compounds in aqueous solution. J. Phys. Chem. B, 115, 9823-9830.

Singleton, V.L. \& Rossi, J.A. (1965): Colorimetry of total phenolics with phosphomolybdic-phosphotungstic acid reagents. Am. J. Enol. Viticult., 16, 144-158.

Stintzing, F.C. \& CARLE, R. (2004): Functional properties of anthocyanins and betalains in plants, food, and in human nutrition. Trends Food Sci. Tech., 15, 19-38.

van CAN, J.G.P., van Loon, L.J.C., Brouns, F. \& BLAAK, E.E. (2012): Reduced glycaemic and insulinaemic responses following trehalose and isomaltulose ingestion: Implications for postprandial substrate use in impaired glucose-tolerant subjects. Brit. J. Nutr., 108, 1210-1217. 